\title{
Dinamik Ağırlık Ölçümü ve Dalgacık Dönüşümü Uygulaması
}

\author{
İsmail YABANOVA, Mehmet YUMURTACI* \\ Afyon Kocatepe Üniversitesi, Teknoloji Fakültesi, Elektrik-Elektronik Mühendisliği Bölümü, 03200/Afyon, Türkiye
}

öz

Günümüzde ürünlerin hızlı ve doğru bir şekilde tartılması üretim sektöründe önemli bir hale gelmiştir. Bundan dolayı ürünlerin hareket halinde iken tartımları yapılarak birim zamanda daha fazla ürünün ölçümünü gerçekleştiren sistemler geliştirilmiştir. Tartım sistemlerinde kullanılan yük hücrelerinin çıkış sinyalinin her zaman salınımlı bir tepkisi vardır ve sinyalin gerçek değerine oturması için belirli bir zamana ihtiyaç duyulmaktadır. Hareket halindeki ürünlerin ölçüm sistemlerinde sistemin ve ürünün hareket halinde olmasından dolayı meydana gelen titreşimlerden kaynaklı yük hücresinin çıkış sinyali oldukça gürültülü olmaktadır. Bu çalışmada bu gürültüleri elimine etmek ve ürünlerin hareket halinde iken istenilen tartım hızlarına ulaşması için dalgacık dönüşümü kullanılarak analiz yapılmıştır.

Anahtar kelimeler: Dalgacık, Ayrık Dalgacık Dönüşümü, dinamik ağırlık ölçümü, yük hücresi

\section{Dynamic Weight Measurement and Wavelet Transform Application}

\begin{abstract}
Today, fast and accurately weighing of products has become important in manufacturing sector. Therefore, while the products move by weighing of them, systems which perform the measurement of more products at per unit time have been developed. Output signal of the load cell used in the weighing system always has an oscillating response and certain time is needed to fit the real value of the signal. In the measurement system of the products moving, the output signal of load cell is quite noisy due to the vibration which occurs from the motions of system and product. In this study, the analysis was performed using wavelet transform to eliminate this noise and to reach the desired weighing speed while the products move.
\end{abstract}

Keywords: Wavelet, Discrete Wavelet Transform, dynamic weight measurement, load cell

\section{Giriş}

Günümüzde üretim kapasitelerinin artmasından dolayı ürünlerin hızlı ve doğru bir şekilde tartılması üretim sektöründe önemli bir hale gelmiştir. Statik tartım bir nesnenin ağırlığını belirlemek için tartım yapılacak platform üzerinde sabitlenmesi ile yapılan tartımdır. Ancak bazı pratik uygulamalarda statik tartım uygun olmayabilir ve nesneleri durdurmadan hareket halinde tartmak daha ekonomik olabilmektedir [1]. İstenilen hızlara ulaşmak için ürünlerin durdurulmadan tartılması gerekmektedir. Ancak ürünlerin ağırlıklarını hareketli olarak ölçen sistemlerde de mekanik titreşimler ölçüm sinyali üzerinde bozucu etkiye neden olmaktadır [2,3]. Bu bozucu etki hareketli sistemin hızına ve ölçülecek olan nesnenin ağırlığına göre değişmektedir [4]. Günümüzde tartım sistemlerinde yük hücreleri yaygın olarak kullanılmaktadır. Yük hücrelerinden elde edilen sinyal salınımlı sönüm yanıtına sahiptir ve ölçüm sinyalinin oturması için zamana ihtiyaç duyarlar. Dinamik ölçüm sistemlerinde kullanılan yük hücrelerinin yapısı gereği salınımlı bir yanıta sahip olması ve sistemdeki titreşimlerden kaynaklanan düşük frekanslı bozucu etkinin birleşmesi ile üstesinden zor gelinecek bir ölçüm sinyali oluşturmaktadır [3]. Titreşimlerden meydana gelen bu bozucu etkilerin ölçüm sinyalinden ayırılması güçtür. Sistemin yanıtını düzeltmek için en çok kullanılan yöntemlerden birisi ölçüm sinyalinin filtrelenmesidir. Hareket halinde ölçüm yapan sistemlerde hız önemli bir faktör olduğundan bu sinyallerin ölçüm

Sorumlu yazar/Corresponding author: Mehmet Yumurtaci, Tel: 027222814 46/15458, e-posta:mehmetyumurtaci@aku.edu.tr, Gönderilme/ Submitted: 31.08.2015, Düzenleme/Revised: 08.01.2016, Kabul/Accepted: 18.02.2016 
sinyalinden ayırılması için kullanılacak yöntemin cevabının da hızlı olması gerekmektedir. Dinamik ölçüm yapılan uygulamalarda ölçüm zamanı ölçüm yapılan sistemin oturma zamanından çok daha kısa olabilmektedir [5]. Filtre bant genişliği ve filtrelenen sinyalin yükselme zamanı arasında önemli bir ilişki vardır. Düşük kesim frekansları filtrelenmiş sinyalin yükselme zamanını arttırdığından ve gecikmeye neden olduğundan dolayı sistemin hızını düşürmektedir [3]. Yüksek kesim frekansları ise sistemin yükselme zamanını azaltmaktadır. Bu durumda ölçüm sinyali istenilen düzeyde filtrelenemediğinden salınımlar meydana gelmektedir. Elde edilen gürültülü ölçüm sinyalinden gürültü sinyalini ayırmak için kullanılan diğer bir yöntem ise dalgacık dönüşümüdür. Dalgacık dönüşümü kullanılarak ölçüm sinyalinden gürültü sinyalinin etkin bir şekilde ayırt edilebildiği görülmüsştür.

Literatürde bu tür sistemler için çeşitli teknikler üzerine çalışmalar yapılmıştır. Bahar ve Horrocks (1998) yaptıkları çalışmada ağırlık ölçüm sisteminin kararlı hale gelmeden önce ölçülen ağırlığın tahminini Artificial Neural Network ile yapmışlardır [6]. Başka bir çalışmada ise dinamik ağırlık ölçüm sistemi için filtre olarak Fuzzy logic estimator kullanılmıştır [7]. Hareket halinde ölçüm sistemlerinin diğer bir uygulama alanı olarak da araçların hareket halindeyken ölçümü gösterilebilir. Hareket halindeyken ölçüm sistemlerinin ağır vasıta ölçüm işlemlerinde kullanılmasının başlıca nedenleri olarak gecikmeleri en aza indirmek ve kilo ihlallerini engellemek sayılabilir [8]. Hareket halindeki araçların ağırlık ölçümünde kullanılan sistemlerde net araç ağırlığını hesaplamak için yeterli ölçüm zamanına ihtiyaç duyulduğundan aracın hızının düşük olması ve ölçümün yapıldığg zeminin yeterli genişlikte olması gerekmektedir. Karayollarındaki hareketli ölçüm sistemlerinde en önemli standartlar araç hareket hızı ve ölçüm hassasiyetidir. Araç tartım sistemlerinden elde edilen sinyal gürültülü ve kısa sürelidir. Hareketli ölçüm sisteminin boyutunu küçültmek ve yüksek hızlarda da doğru olarak ölçümü gerçekleştirmek için ayrık dalgacık dönüşüm tabanlı bir sinyal işleme metodu önerilmiştir [9]. Hareketli araç ölçüm sistemleri sabit araç ölçüm sistemleri ile karşılaştırıldığında zamandan tasarruf, yüksek hassasiyet ve trafik akışını etkilememe gibi avantajlara sahiptir. Dinamik lastik güçlerinin etkisi ve ölçüm sisteminden kaynaklı ölçüm sinyalinde meydana gelen gürültülerin süzülmesi için fiber optik hareketli ölçüm sensörü ve ayrık dalgacık dönüşümünün birlikte kullanıldığı bir sistem önerilmiştir [8,10]. Jacob ve diğ. (2010) yaptıkları çalışmada aşırı yüklenmiş araçların meydana getirdiği sorunlardan ve hareket halinde tartım sistemlerinin potansiyelinden bahsetmişlerdir [11]. Liljencrantz ve diğ.
(2007) yaptıkları çalışmada hareket halinde tartım sistemini demiryollarına uygulamışlardır [12].

$\mathrm{Bu}$ çalışmada hareket halindeki ürünlerin tartım sinyalinde meydana gelen gürültülerinin giderilmesinde dalgacık dönüşümü kullanılmıştır. Ölçüm sinyaline dalgacık dönüşümü uygulanarak ürünlerin istenilen hızlarda stabil ağırlıklarının rahatlıkla belirlenebildiği görülmüştür.

\section{Dalgacık ve Dalgacık Dönüşümü}

Dalgacık, sıfır ortalama değere sahip düzensiz bir şekli olan ve sinırlı süreli küçük dalgadır. Şekil 1'de görüldüğü gibi

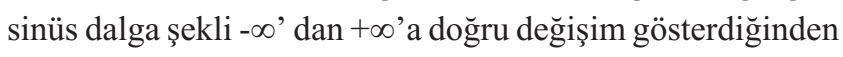
zamanla sınırlı değildir, düzgün bir şekle sahip olup değişimi tahmin edilebilmektedir [13].
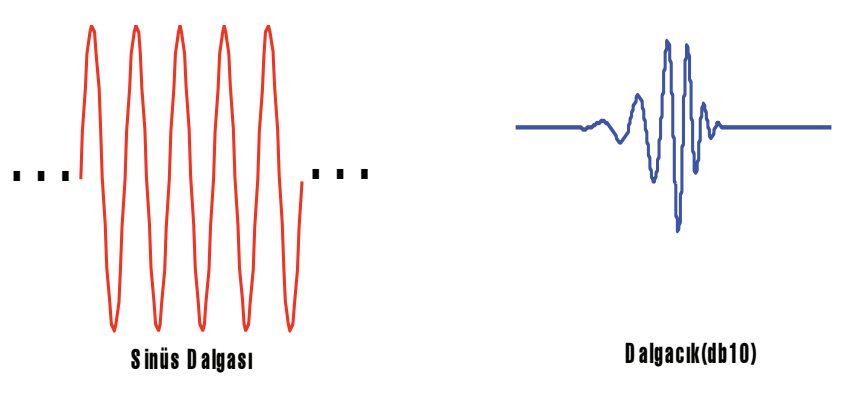

Şekil 1. Sinüs ve dalgacığın dalga şekilleri [13].

Fourier Dönüşümü (FD), bir sinyalin zaman bölgesindeki gösterimini frekans bölgesi gösterimine dönüştürmek için matematiksel bir tekniktir. Frekans bölgesine dönüşüm işleminde zaman bilgisi kaybolmaktadır [14]. Kısa Zamanlı Fourier Dönüşümü (KZFD) sinyalin zaman ve frekans bilgisinin her ikisini de içermesine rağmen analiz penceresinin boyutunun sabit olmasından dolayı sınırlı bir frekans çözünürlüğüne sahiptir [15]. İncelenen sinyaldeki bilginin çoğu frekans içeriğinde saklıdır. Dalgacık dönüşümü kullanımılla sinyaldeki frekans ve zaman bilgisi aynı anda elde edilebilmektedir. Durağan olmayan sinyalin analizinde FD ve KZFD kullanımı yeterli sonuçlar vermediğinden daha iyi sonuçlar dalgacık dönüşümü kullanılarak elde edilebilmektedir [16]. Farklı frekans aralıklarında en uygun zaman-frekans çözünürlüğünü elde edebilmek için düşük frekanslarda geniş pencere yüksek frekanslarda dar pencere kullanımı yani değişken boyutlu pencereleme tekniği dalgacık dönüşümünün ana avantajıdır [17]. Şekil 2'de farklı sinyal işleme tekniklerine ait pencereleme yöntemleri bir arada verilmiştir. 


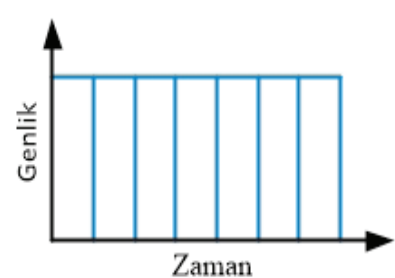

Zaman Bölgesi (Shannon)

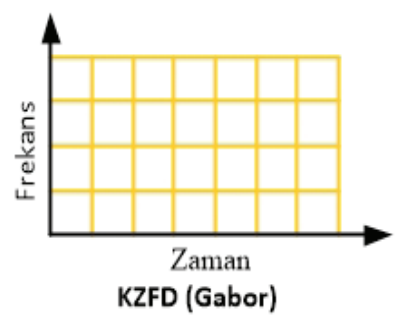

Şekil 2. Sinyallerin farklı tekniklerde gösterimi ve pencereleme özellikleri [13].

Dalgacık dönüşümü, konuşmacı tanıma, görüntü işleme, motor arıza tespitinde, güç sistem analizinde, arıza sınıflandırmada, hastalık teşhisi gibi birçok değişik alanda yaygın olarak kullanılan etkili bir araçtır. Sürekli Dalgacık Dönüşümü (SDD) ve Ayrık Dalgacık Dönüşümü (ADD) olmak üzere ikiye ayrılmaktadır.

SDD'de sinyalin bir parçası seçilen ana dalgacık ile karşılaştırılarak korelasyonu bulunur. Tüm sinyal parçaları ile dalgacığın ötelenerek karşılaştırılması işlemi bittiğinde dalgacığın ölçeği değiştirilerek işlem tekrarlanır. Öteleme ve ölçekleme işleminin sonucu olarak katsayılar elde edilir [18]. Bir sinyalin sürekli dalgacık dönüşümü, $\psi(t)$ dalgacık fonksiyonunun ölçeklenmiş ve ötelenmiş formunun çarpılarak sinyalin integralinin alınması işlemidir [15]. SDD tekniği hesaplama işlemi için çok fazla zamana ve elde edilen verilerin saklanması için büyük bir bellek alanına gereksinim duymaktadir [19]. ADD, bir sinyalin zaman ve frekansın etkin bir şekilde hesaplanmasının kompakt gösterimine imkân sağlayan dalgacık dönüşümünün özel bir durumudur [20]. Bir $x(t)$ sinyalinin ayrık dalgacık dönüşümü denklem (1)'deki gibi bulunur [21].

$$
x(t)=\sum_{k} a_{j}(k) \varphi_{k}\left(2^{j} t-b\right)+\sum_{j} \sum_{k} d_{j, k} \psi\left(2^{j} t-b\right)
$$

j ölçekleme faktörü ve $b$ zamanda öteleme $\psi$ dalgacık fonksiyonu ve $\varphi$ ölçekleme fonksiyonu göstermektedir. $a_{j}$ yaklaşım katsayıları ve $d_{j}$ detay katsayıları denklem (2)'deki gibi hesaplanır [21].

$$
\begin{aligned}
& a_{j}(k)=2^{j} \int x(t) \varphi\left(2^{j} t-k\right) d t \\
& d_{j}(k)=2^{j} \int x(t) \psi\left(2^{j} t-k\right) d t
\end{aligned}
$$

ADD analizinde, orijinal sinyal birbirini tamamlayan alçak ve yüksek geçiren iki filtre yoluyla eşit olarak alçak ve yüksek frekanslı bileşenlere ayrılır [22,23]. Alçak geçiren filtre yöntemiyle işlenen sinyalden elde edilen yüksek ölçekli düşük frekanslı yeniden oluşturma bileşenine yaklaşım adı verilmekte ve "A" harfi ile gösterilmektedir. Yüksek geçiren filtre yoluyla filtrelenen sinyalden elde edilen düşük ölçekli yüksek frekanslı yeniden oluşturma bileşenine detay adı verilmekte ve "D" harfi ile gösterilmektedir [24]. S sinyaline ikinci seviyeden ADD uygulanması durumunda elde edilen yaklaşım ve detay bileşenleri ile frekans aralıkları Şekil 3'te verilmiştir.

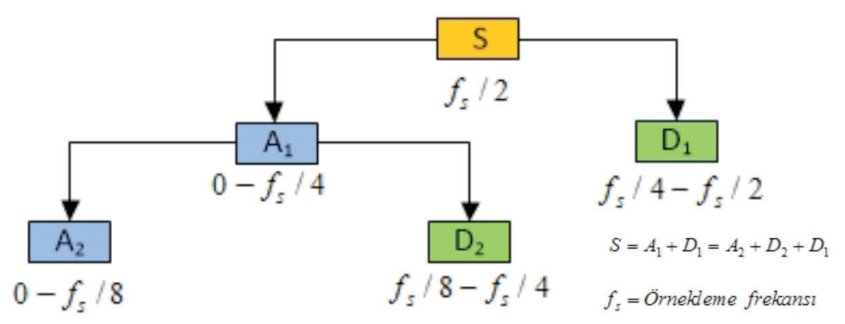

Şekil 3. S sinyalinin 2. seviye ADD ile bileşenlerine ayrilması [13].

$\mathrm{Bu}$ çalışmada hareketli yumurta ölçüm sisteminden alınan ağırlık verileri üzerindeki gürültüyü süzmek için ADD kullanılmıştır. Değişik dalgacıklar kullanılarak farklı seviyelerde ayrıştırma işlemi tekrarlanarak en uygun ayrıştırma seviyesi ile ana dalgacık tespit edilmeye çalışılmıştır.

\section{Hareket Halinde Ürün Ölçüm Sistemi}

Gerçekleştirilen ölçüm sistemi elektronik ve mekanik olmak üzere iki kısımdan oluşmuştur. Elektronik kısmı mikrodenetleyici tabanlı bir kart ve bu kartın yazılımdan oluşmaktadır. Yük hücresinden alınan sinyal öncelikle yükseltilip diferansiyel $\Delta \Sigma$ modülatör ile dijital sinyale çevrilmektedir. Ardından seri haberleşme arabirimi üzerinden mikrodenetleyici tarafindan okunmaktadır. Mekanik kısım ise ürünlerin yük hücresi platformu üzerinden hareket halinde geçerek tartılmalarını sağlayacak şekilde tasarlanmıştır. 
Tasarlanan mekanik sistem ise yuvarlak forma sahip (yumurta, portakal vb.) ürünlerin ağırlıklarının ölçülmesine uygundur. Tartılmak istenen ürünler taşıyıcı çubuklar vasıtasıyla eğimli bir yüzey üzerinden yuvarlanarak yatay olarak konumlandırılmış yük hücresi platformu üzerinden geçmektedirler. Yük hücresi platformu üzerine geldiklerinde hızlarındaki azalmadan dolayı taşıyıcı çubuklar ile olan temasları ortadan kalkmakta ve ağırlık ölçümünü etkileyecek bir kuvvete maruz kalmadan yük hücresi platformundan geçmektedirler. Bu sayede tartılmak istenen ürün durdurulmadan hareket halinde iken tartılmakta ve istenilen tartım hızlarına ulaşılmaktadır. Şekil 4'te hareket halinde ürün tartım sisteminin akış şeması verilmiş̦ir.

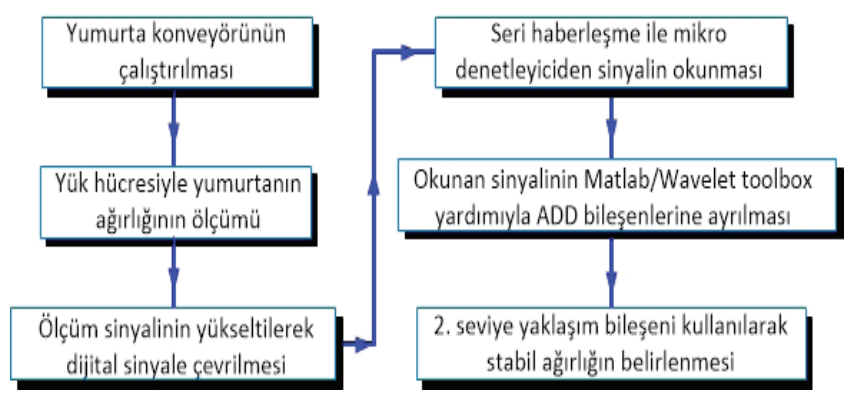

Şekil 4. Hareket halinde ürün tartım sistemi akış şeması.

\section{Deneysel Ölçümler ve Dalgacık Uygulaması}

Tasarlanan sistem kullanılarak ağırlık ölçümleri gerçekleştirilmiştir. Hareket halinde tartılan 6 adet farklı yumurtanın ağırlıklarına ait ölçüm sinyali Şekil 5' te verilmiştir. Sistemin ve ağırlığı ölçülecek ürünün hareketli olmasından dolayı oluşan titreşimler ölçüm sinyali üzerinde bozucu etkiye neden olmaktadır. Bundan dolayı ürünlerin ağırlıklarının belirlenmesi mümkün olamamaktadır. $\mathrm{Bu}$ çalışmada ölçüm sinyalinden gürültülerin ayırt edilmesi için ADD kullanılmıştır.

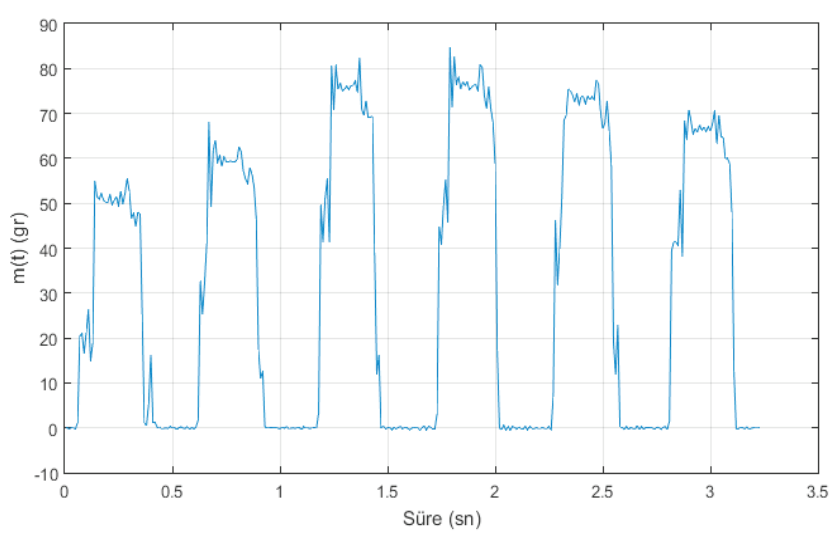

Şekil 5. Altı farklı yumurtanın ölçüm sinyali.
Şekil 5'te verilen ölçüm sinyaline Haar ve Bior 1.1 dalgacıklarının kullanıldığ 1 2. seviye ADD uygulandığında elde edilen yaklaşım bileşenleri ile gerçek ağılık verileri Şekil 6' da verilmiştir.

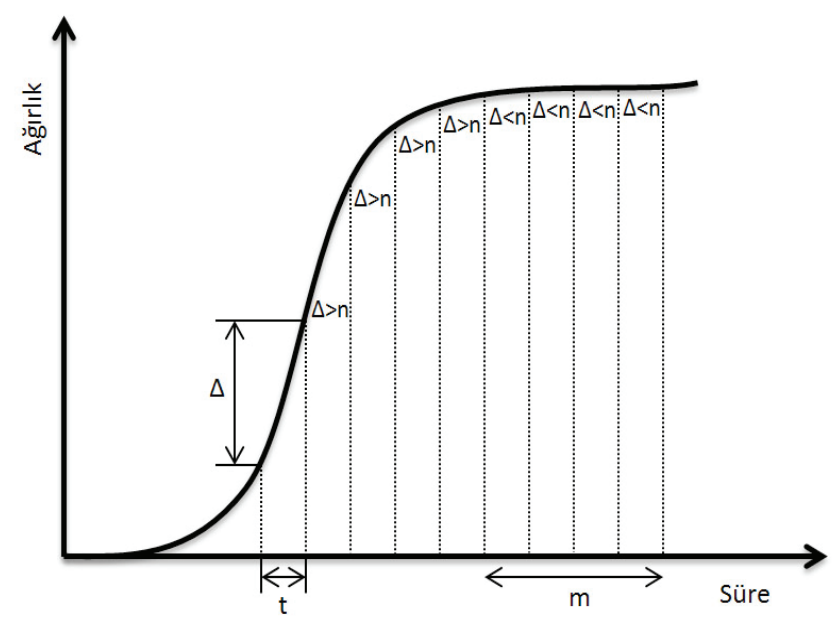

Şekil 6. Gerçek ağırlık verisi ve ADD ile filtrelenmiş veriler.

Ölçüm sonucunda elde edilen sinyale ADD uygulandığında bu verilerin başarılı bir şekilde gürültüden arındırıldığı ve ürünlerin ağırlıklarının belirlenebilir hale geldiği görülmektedir. Tartılan ürünün tartım süresinde ağırlığının stabil olduğu anı belirlemek için Şekil 7' de gösterilen basit bir yöntem kullanılmıştır. Bu yöntemde;

\section{$\Delta$ : Ağırlıklardaki değişim, \\ t: Ölçüm süresi}

m: Stabil halde ölçülen ağıllık ölçümü sayısı (5 seçilmiştir) $\mathrm{n}$ : Stabil aralığ $(0.5 \mathrm{~g}$ seçilmiştir $)$

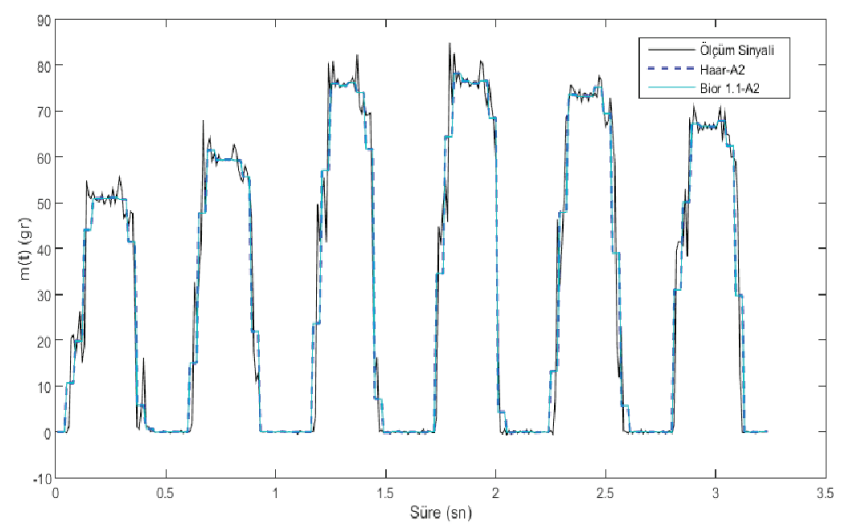

Şekil 7. Stabil ağırlık belirleme şeması. 
Şekil 7'den de anlaşılacağ 1 gibi tartılan nesnenin stabil ağırlığının belirlenebilmesi için bir önceki veri ile o anki veri arasındaki değişimin 0.5 gr dan küçük olması ve bu şekilde 5 tane art arda veri gelmesi gerekmektedir. Ölçüm sinyaline uygulanan ADD' nin analizi de bu şekilde yapılmıştır.

Yapılan ölçümlere uygulanan ADD'lerin performansları karşılaştırıldığında istenilen hızlarda Haar 58, Bior 1.1 ise 61 adet veride ölçüm anında bir önceki ağılık değeri ile 0,5 gramın altında değişiklik olmuştur.

\section{Sonuç}

Günümüzde üretim sektöründe ürünlerin hareket halinde iken hızlı ve doğru olarak tartılması önem arz etmektedir. Böylece birim zamanda daha fazla ürünün ölçümünü gerçekleştiren sistemler geliştirilmiştir. Hareket halindeki ürünlerin ölçüm sisteminde kullanılan yük hücrelerinin çıkış sinyali gerek ürünün hareketinden gerekse sistemdeki titreşimlerden dolayı gürültülü olup gerçek değerine oturması için zamana ihtiyaç duyulmaktadır. Ölçüm sinyali üzerindeki gürültü sinyallerini tam olarak tespit etmek için dalgacık dönüşümünden faydalanılmıştır. ADD kullanılarak ölçüm sinyalinin farklı seviye ve dalgacık aileleri ile analizi yapılmıştır. En iyi sonuç Bior 1.1 dalgacı̆̆ kullanılarak 2. seviye ADD analizi ile elde edilen yaklaşım katsayısı kullanılarak sağlanmıştır. Ölçüm sinyalindeki gürültü süzüldükten sonra stabil ağırlık belirleme işleminden faydalanılarak ürünün net ağırlığı tespit edilmektedir.

\section{KAYNAKLAR}

[1] Niedźwiecki, M., Wasilewski, A. (1996). Application of adaptive filtering to dynamic weighing of vehicles. Control Engineering Practice, 4(5), 635-644.

[2] Yamazaki, T., Sakurai, Y., Ohnishi, H., Kobayashi, M., Kurosu, S. (2002). Continuous mass measurement in checkweighers and conveyor belt scales. Proceedings of the 41st SICE Annual Conference, Osaka, 5-7 Aug.

[3] Boschetti, G., Caracciolo, R., Richiedei, D., Trevisani, A. (2013). Model-based dynamic compensation of load cell response in weighing machines affected by environmental vibrations. Mechanical Systems and Signal Processing, 34(12), 116-130.

[4] Pietrzak, P., Meller, M., Niedźwiecki, M. (2014). Dynamic mass measurement in checkweighers using a discrete timevariant low-pass filter. Mechanical Systems and Signal Processing, 48(1-2), 67-76.

[5] Yamazaki, T., Ono, T. (2007). Dynamic problems in measurement of mass-related quantities. SICE, 2007 Annual Conference, Takamatsu, 17-20 Sept.

[6] Bahar, H.B., Horrocks, D.H. (1998). Dynamic weight estimation using an artificial neural network. Artificial Intelligence in Engineering, 12(1-2), 135-139.

[7] Halimic, M., Balachandran, W., Enab, Y. (1996). Fuzzy logic estimator for dynamic weighing system. Fuzzy Systems, 1996., Proceedings of the Fifth IEEE International Conference on, New Orleans, LA, 8-11 Sep.

[8] Jian, X., Bin, M. (2010) . Investigation of discrete wavelet transform for signal de-noising in weight-in-motion system. Future Computer and Communication (ICFCC), 2010 2nd International Conference on, Wuhan, 21-24 May.

[9] Xiao, J., Lv, P. (2009). Application of wavelet transform in weigh-in-motion. Intelligent Systems and Applications, 2009. ISA 2009. International Workshop on, Wuhan, 23-24 May.

[10] Bin, M., Xinguo, Z. (2010). Discrete wavelet transform for signal processing in weight-in-motion system. Electrical and Control Engineering (ICECE), 2010 International Conference on, Wuhan, 25-27 June.

[11] Jacob, B., Beaumelle, V.F.L. (2010). Improving truck safety: potential of weigh-in-motion technology. IATSS Research, 34(1), 9-15.

[12] Liljencrantz, A., Karoumi, R., Olofsson, P. (2007). Implementing bridge weigh-in-motion for railway traffic. Computers \& Structures, 85(12), 80-88.

[13] Misiti M., Misiti Y., Oppenheim G., Poggi J.M. (2002) Wavelet toolbox for use with MATLAB, User's Guide Version 2, The MathWorks.

[14] Li, S., Wen, J. (2014). A model-based fault detection and diagnostic methodology based on PCA method and wavelet transform. Energy and Buildings, 68, 63-71.

[15] Ocak, H. (2009). Automatic detection of epilepti seizures in EEG using discrete wavelet transform and approximate entropy. Expert Systems with Application, 36(2), 2027-2036.

[16] Aggarwal, R., Singh, J.K., Gupta, V.K., Rathore, S., Tiwari, M., Khare, A. (2011). Noise reduction of speech signal using wavelet transform with modified universal threshold. International Journal of Computer Applicaitons, 20(5), 1419.

[17] Avci, E. (2008). Comparison of wavelet families for texture classification by using wavelet packet entropy adaptive network based fuzzy inference system. Applied Soft Computing, 8(1), 225-231.

[18] Giaouris, D., Finch, J.W. (2008). Denoising using wavelets on electric drive applications. Electric Power Systems Research, 78(4), 559-565.

[19] Wu, J.D., Liu, C.H. (2008). Investigation of engine fault diagnosis using discrete wavelet transform and neural network. Expert Systems with Applicaitons, 35(3), 12001213.

[20] Panigrahi, B.K., Sinha, S.K., Mohapatra, A., Dash, P., Mallick, M.K. (2011). A comparative study of signal processing and pattern recognition approach for power quality disturbance classification. IETE Journal of Research, 57(1), 5-11.

[21] Goudarzi, M., Vahidi, B., Naghizadeh, R.A., Hosseinian, S.H. (2015). Improved fault location algorithm for radial distribution systems with discrete and continuous wavelet 
analysis. International Journal of Electrical Power \& Energy Systems, 67, 423-430.

[22] Martis, R.J., Acharya, U.R., Min, L.C. (2013). ECG beat classification using PCA, LDA, ICA and discrete wavelet transform. Biomedical Signal Processing and Control, 8(5), 437-448.

[23] Bakar, A.H.A., Ali, M.S., Tan, C.K., Mokhlis, H., Arof, H., Illias, H.A. (2014). High impedance fault location in $11 \mathrm{kV}$ underground distribution systems using wavelet transforms. International Journal of Electrical Power \& Energy Systems, 55, 723-730.

[24] El-Zonkoly, A.M., Desouki, H. (2011). Wavelet entropy based algorithm for fault detection and classification in FACTS compensated transmission line. International Journal of Electrical Power \& Energy Systems, 33(8), 1368-1374. 